\title{
Trade-offs betw een melanization, development time and adult size in Inachis io and Araschnia levana (Lepidoptera: Nymphalidae)?
}

\author{
J ACK J . WINDIG* \\ Department of Zoology, University of Stockholm, 10691 Stockholm, Sweden and Department of Biology, University \\ of Antwerp (UIA), Universiteitsplein 1, 2610 Antwerpen, Belgium
}

\begin{abstract}
Effects of melanization in the juvenile stages of the European map butterfly (Araschnia levana) and the peacock butterfly (Inachis io) on the life history traits, larval and pupal development time and size at maturity, and on adult melanization were investigated. Pupae and 5th instar larvae of $A$. levana vary in degree of melanization, the latter possibly determined by a single major gene. Variation in melanization in $I$. io occurs only in the pupal stage and is under low genetic control. In both species life history traits and adult melanization are influenced by juvenile melanization, both at phenotypic and genetic levels. Many of the relationships are consistent with trade-offs, e.g. melanized 5th instars of $A$. levana grow more slowly in early instars and $I$. io adults from melanized pupae are smaller and less black. However, some results are inconsistent with a trade-off hypothesis. Possible adaptive and physiological explanations are discussed. Araschnia levana shows seasonal polyphenism in wing pattern; pale larvae produced more spring forms, probably resulting from slower growth in the 5th instar. Genetic correlations across environments for larval development time and adult size are to a large extent influenced by larval melanization.
\end{abstract}

Keywords: colour, genetic correlation across environments, life history, melanin, quantitative genetics, trade-off.

\section{Introduction}

Variation in and genetics of both life history and morphology have been studied intensively in order to understand evolutionary change and constraints upon them. Life history traits are directly related to fitness and natural selection on these traits is generally directional (Stearns, 1983). Morphological traits are less intimately connected to fitness and natural selection is often stabilizing (Roff, 1997). Heritability $\left(h^{2}\right)$ of life history traits is generally lower than for morphological traits (Mousseau \& Roff, 1987). This paper explores the extent to which morphology and life history may evolve independently. Relationships in two Lepidoptera species between two life

*Correspondence: Department of Zoology, University of Stockholm, 10691 Stockholm, Sweden. E-mail: jack.windig@zoologi.su.se history traits, juvenile development time and adult size, and one class of morphological traits, melanization, are examined both at phenotypic and genetic levels.

Short juvenile development time and large adult size are highly relevant to fitness (Nylin \& Gotthard, 1998), and so is variation in melanization (Majerus, 1998). The latter has been the focus of many studies in evolutionary biology, including larval (e.g. Porter, 1982; Fields \& McNeil, 1988; Goulson, 1994), pupal (e.g. Wiklund, 1975; Hazel \& West, 1996) and adult butterflies (e.g. Watt, 1968; Windig et al., 1994; Kingsolver, 1995; Van Dyck et al., 1997). These studies have analysed the direct effect of melanization on temperature and/or conspicuousness or indirect effects on for example behaviour or avoidance of predation. The classic case of natural selection with Biston betularia is an example of the latter, in which differences in wing melanization and conse- 
quent crypsis affect predation rate (Kettlewell, 1973; Majerus, 1998; but see Grant et al., 1996).

Adaptation is probably not the only process influencing melanin and life history traits, because constraints may be operating. Both faster growth and larger size may be traded off against one another or against costly traits such as melanin production, which requires protein (Blois, 1978). Thermoregulation may be more effective in melanized individuals, enabling a higher growth rate (Dennis, 1993; De Jong et al., 1996) or melanin production in one stage may not be independent of another stage (e.g. Smith et al., 1988). High melanin production in for example pupae may continue in the adult stage. On the other hand, it may deplete resources for melanin production leading to a reduction of melanization in adults. If these constraints have a genetic basis they may influence evolution of colour patterns.

High $h^{2}$ s have been found frequently for melanization in adults. Examples include size of black pattern elements in butterflies (e.g. Brakefield \& van Noordwijk, 1985; Kingsolver \& Wiernasz, 1991; Windig, 1994b) and ladybirds (Holloway et al., 1995) and intensity of black coloration in the butterfly Bicyclus anynana (Windig 1994a,b). Little is known about the genetic basis of melanization in juvenile stages. In Papilio polyxenes (Hazel \& West, 1996), pupal colour is mainly determined by environmental factors, but some genetic control is involved, whereas in Danaus chryssipus pupal colour is mainly under genetic control (Smith et al., 1988). Genetic correlations between juvenile melanization and life history traits or melanization in later life stages have not been described hitherto.

In this paper I analyse effects of juvenile melanization across life stages for two nymphalid butterflies. Araschnia levana, the European map butterfly, has pale and dark larval forms, whereas Inachis io, the peacock butterfly, has two pupal forms, one green and the other dark brown. In both species melanins are responsible for the dark coloration (Koch, 1992; Starnecker, 1996). Butterflies were raised in relatively cool spring and late summer conditions and were compared, both phenotypically and genetically, for melanization across life stages, between species and between spring and summer butterflies.

I adopt the following working hypotheses.

(1) Melanization on the one hand, and variation in development time and adult size on the other, are related. Melanization may involve a cost in the form of slow growth and small adult size, because its production is costly. Alternatively, because of superior absorbence of radiant heat it may also confer the benefit of faster growth under relatively cool conditions.

(2) Melanization in juvenile and adult stages is related, because melanin production over the life cycle is constrained. Thus butterflies resulting from dark pupae or larvae have smaller and/or less intensively black wing pattern elements than butterflies from pale pupae or larvae.

(3) Melanization has a genetic basis, although only a small one in the pupal stage, where it is mainly determined by environmental factors. Life history traits have lower heritabilities than melanization. The relationships between juvenile melanization, life history, and adult melanization have a genetic basis.

\section{Materials and methods}

\section{Study species}

Inachis io and A. levana are common in Belgium (Maes \& Van Dijck, 1996) feeding on stinging nettle Urtica dioica. Araschnia levana shows a striking seasonal polyphenism: the spring form induced by short days in the larval stage has orange wings with black spots; the summer form induced by long days has black wings with a white band and some small orange spots. Araschnia levana has two or three generations a year and hibernates as a pupa. Larvae vary in the fifth and last stage almost discretely between black and light brown, whereas pupae vary continuously from light to dark brown. Inachis io has only one adult form (Fig. 1) and one larval form; 5th instar larvae are jet black with small white dots. The pupae vary more or less discretely from entirely yellowish green to dark brown. Inachis io has one or two generations a year and overwinters as an adult.

\section{Breeding}

Both study species were raised in the laboratory following Pullin (1986). For A. levana, summer generation females were caught in the field and allowed to lay eggs in small cages placed over nettles in a garden. Of the $I$. io females caught in a similar way only one laid eggs. Additional groups of 1st or 2nd instars were collected in the field. DNA-fingerprinting was used to determine the relationships within the groups, either resulting from egg batches or larvae collected in the field, and indicated that all groups consisted of full-sibs (unpubl. data).

Two days after hatching ( $A$. levana), when the larvae were sufficiently robust to withstand handling, 
or when the larvae were found in the field (I. io), they were brought to the laboratory. Families were split between a long day (LD) (16h light/8 h dark) and a short day (SD) (12/12 l/d) climate room. Temperature in both climate rooms varied between $19^{\circ} \mathrm{C}$ and $21^{\circ} \mathrm{C}$, the $\mathrm{SD}$ room tending to be some tenths of degrees cooler. Eleven families of $I$. io were raised in June and July 1996 and split equally between environments. Sixteen families of $A$. levana were raised in July and August. For $I$. io, all larvae of each family were raised. Survival was high (about

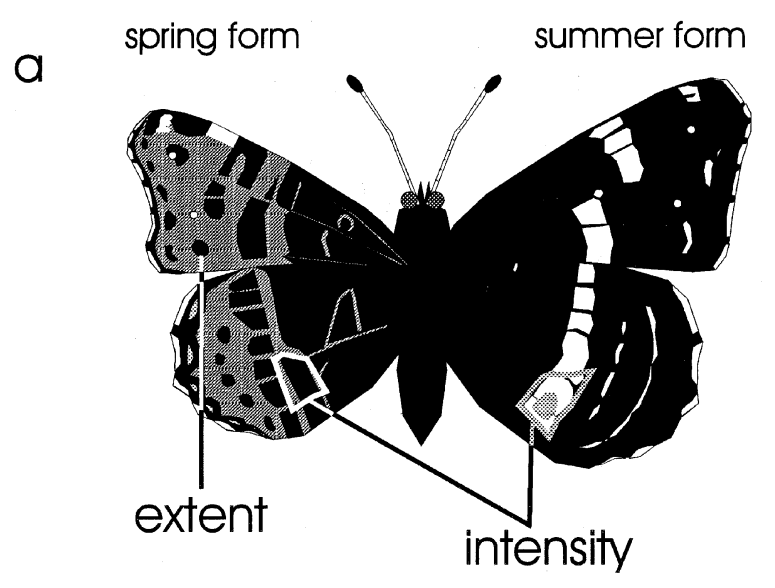

$\mathrm{b}$

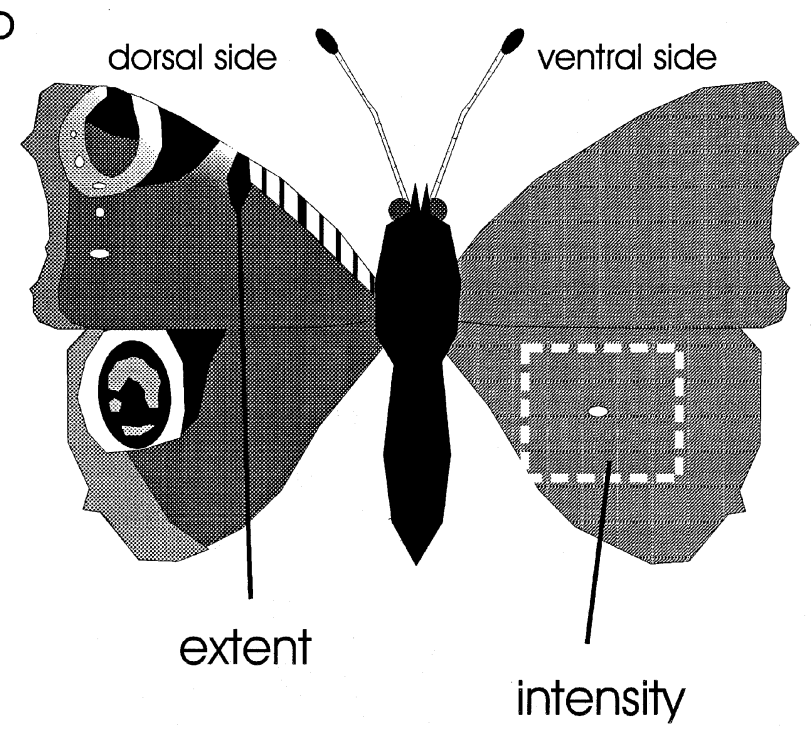

Fig. 1 Measurements of melanization in adult (a) Araschnia levana and (b) Inachis io. Extent of melanization: area of indicated spots. Intensity of melanization: grey value of indicated areas. For A. levana total area of all black parts was also measured for extent of melanization.
$70 \%$ ) and consequently large numbers of adults were raised (on average about 100 per family). To avoid space problems a maximum of thirty $A$. levana larvae was used from each family in each environment. Two families with about thirty larvae were raised in the LD environment only.

Families were placed in Petri dishes with fresh nettle leaves. At the start of the 2nd instar they were split into groups of five and at the 4th instar into groups of two. Inachis io were raised singly in the final 5th instar. Fresh leaves were provided every other day. Petri dishes were stacked in piles of five. All families were split equally over all five levels and over piles placed at the sides or in the middle. Each Petri dish was placed one level higher when fresh food was provided, except the top dishes which went to the bottom. After pupation, pupae were placed in small peat pots, with Petri dish tops as lids. SD pupae of $A$. levana, destined to produce spring forms, went into diapause to overwinter, as did some of the LD pupae. Those failing to eclose within 4 weeks after pupation were stored in a cold room $\left(0-5^{\circ} \mathrm{C}\right)$ until 1 February the next year (about 4 months). One day after eclosion adults were placed in a freezer and stored at $-70^{\circ} \mathrm{C}$ together with their pupal case in glassine envelopes.

\section{Measurement of melanization}

Fifth instar larvae of $A$. levana were visually classified as dark or pale, most being easily categorized; the remainder were considered intermediates. An image analyser (Windig, 1991) (consisting of a video CCD colour camera (JAI-2040) connected to a Pentium-PC with one frame grabber (Matrox Millennium) that digitized images as 24-bit colour images) was used to quantify melanization in the pupal and adult stages. Macros were written for the analyses with OPTIMAs 5 software.

Variation in pupae was measured on the wing case as average grey value on a scale of $0(=$ dark) to 255 (= pale). In adults both intensity of black coloration and size of black pattern elements were quantified. In $A$. levana the only part where the intensity of black coloration varied beyond measurement error was the lower part of the band on the hindwing (Fig. 1) which was measured as average grey value on the dorsal side. In $I$. io intensity was measured as the average grey value of the ventral side of the hindwing (Fig. 1).

To evaluate the extent of black parts in the wing, one black spot was measured (Fig. 1). It was selected for ease and accuracy of measurement in a pilot study where the size of all black pattern elements 
was measured in 40 butterflies. The sizes of all these elements were so strongly correlated that measurement of only one element involved little loss of information. For both species one spot on the forewing was selected (Fig. 1). In the summer form of $A$. levana all black pattern elements on the forewing are merged and the total area of all black pattern elements was measured. The areas were log-transformed before analysis to obtain a normal distribution. In $I$. io the log-transformed area of the black spot was highly correlated to the log-transformed area of the wing. To remove this allometric effect, residuals of the regression were used in the analyses.

\section{Measurement of life history traits}

Juvenile development time and adult size were measured as life history characters. For $I$. io the date of egg laying was unknown, so larval development period was measured from the start of the 3rd instar until pupation. For $A$. levana larval development time was split into the period up to the 5th instar and the 5th instar itself; variation in melanization occurred only in the 5th instar. Pupal development time was measured for both species as number of days from pupation to eclosion. Adult size was measured with the image analyser as forewing area $\left(\mathrm{mm}^{2}\right)$. Both development times and adult size were log-transformed to obtain normal distributions for analysis.

\section{Statistical analysis}

Multifactor ANOvAs were used to evaluate the influence of larval melanization in A. levana on melanization in later stages and on the life history characters. Besides larval coloration, sex and day length/form were used as factors. LD induced both spring and summer forms, SD only spring forms; therefore day length/form had three levels: LD spring, LD summer and SD spring.

Pupal colour in A. levana varies continuously (Fig. 2). Therefore correlation coefficients were used to evaluate the influence on adult wing pattern and on life history characters. Pupal colour in $I$. io shows a bimodal distribution with overlapping tails (Fig. 2). Therefore it was analysed as discrete variation with continuous variation within classes (dark/pale). The intermediate grey value that occurred at the lowest frequency was used to separate the two classes. The influence of pupal melanization categories was evaluated with multifactor ANOVAS, similar to those used for larval melanization in A. levana. The influence of the remaining variation was evaluated with correlation coefficients.

\section{Genetic analysis}

Frequencies of black and pale larvae in A. levana were tested for deviation from Mendelian frequencies with a $\chi^{2}$-test. For the remaining, continuous, variables quantitative genetic analyses were performed on sexes and forms separately. Additive and residual (co-) variance components were determined by a Restricted Error Maximum Likelihood (REML) analysis, which has the advantage that it gives unbiased estimates that can be directly tested for a difference from 0 (Shaw et al., 1995), even if family sizes are unbalanced. Because data sets had a full-sib structure, estimates of additive variance also contained part of the dominance and interaction components as well as variance caused by maternal
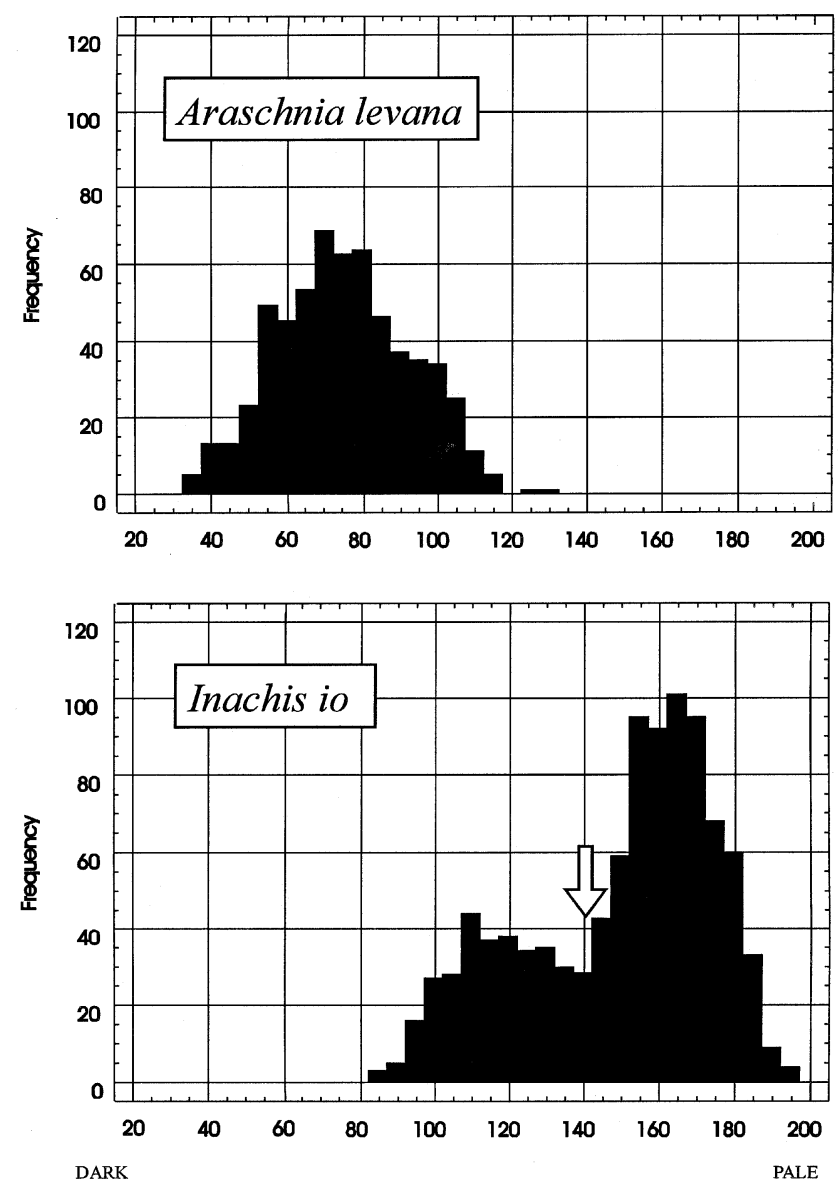

Fig. 2 Variation of pupal coloration of Araschnia levana and Inachis io as measured on a grey scale of 0-255. Arrow indicates grey value used to distinguish dark and pale pupae in $I$. io. 
effects. The REML-analyses were performed with the nf3 program (R. G. Shaw \& F. A. Shaw, $1992-$ Quercus: programs for quantitative-genetic analysis using maximum likelihood; published electronically on the Internet, available via anonymous ftp from ftp.bio.indiana.edu; directory path biology/quantgen/ quercus) adapted for use on a PC. $h^{2}$ s were calculated as the quotient of the additive variance component $\left(V_{\mathrm{A}}\right)$ and the total or phenotypic variance $\left(V_{\mathrm{P}}\right)$. Heritability for pupal coloration in $I$. io was calculated using the method of Roff (1997) for threshold traits. Genetic correlations between juvenile melanization and other traits were calculated using the REML program. Genes causing melanization in juvenile stages may influence $h^{2}$ s of other traits and genetic correlations between them. Estimations of $h^{2}$ and genetic correlation were therefore repeated within dark and pale categories of juvenile coloration to analyse to what extent this was the case.

\section{Results}

\section{Survival}

742 adult $A$. levana butterflies were raised, a survival rate to adult of $76.5 \%$. Significantly more larvae survived in LD $(396,85.4 \%)$ than in SD (346, $\left.72.8 \%, \chi_{1}^{2}=17.11, P<0.001\right)$. Survival was highest for dark $(83.6 \%)$, lowest for intermediate larvae $(72.0 \%)$ and intermediate for pale larvae $(78.9 \%)$. This difference is significant $\left(\chi_{2}^{2}=7.31, P=0.026\right)$. However, if LD and SD data are analysed separately results are not significant $\left(\mathrm{LD}, \chi_{2}^{2}=3.38, P=0.185\right.$; SD, $\left.\chi_{2}^{2}=4.77, P=0.092\right)$. $1042 I$. io adults were raised, a survival rate of $69.9 \%$. Survival was significantly lower in SD $(n=478,62.8 \%)$ than in LD $(n=564,71.4 \%)\left[\chi_{1}^{2}=12.94, P=0.0003\right]$. A possible difference in survival between differently coloured pupae could not be measured because the haemolymph of all pupae that died turned black.
J uvenile melanization in A. levana

Over $83 \%$ of larvae were estimated as dark or pale, the remaining $16.8 \%$ as intermediates. Slightly more pale than dark larvae occurred, especially for LD females (Table 1). There was, however, no significant difference in the frequencies of the colour classes between sexes $\left(\chi_{2}^{2}=3.11, P=0.29\right)$ nor was there a significant difference between LD and SD $\left(\chi_{2}^{2}=3.91, P=0.145\right)$.

The frequency of dark larvae within $A$. levana families ranged from 1.3 to $93.9 \%$. Families had about the same percentage of dark and pale larvae in LD and SD. The correlation between SD and LD of the percentage of dark and pale larvae is high ( $r=0.789, n=15, P=0.0007)$. If larval colour is determined by a simple diallelic system with dominance, 'Mendelian' frequencies of $0,50,75$ or $100 \%$ dark larvae (or pale larvae if dominance is reversed) are expected in all families. This is not the case. Out of 16 families, at least three families do not show Mendelian frequencies, regardless of whether intermediates are grouped with pale or dark individuals and whether dark or pale is considered dominant.

Pupal coloration varies continuously in A. levana. Overwintering pupae (especially LD spring) are palest whereas the darkest are SD females. Interactions between daylength/form, sex and larval colour are not significant (Table 2). Heritability for pupal coloration is significantly different from 0 (males: LD 56.5\%, SD 28.0\%; females: LD $43.3 \%$, SD $39.9 \%$ ).

\section{Life history traits in A. levana}

Males and females did not have significantly different development times through instars 1-4 (Fig. 3) but in the 5th instar females took longer. Larvae growing under SD developed more slowly in all instars. Heritabilities for larval development times are high and significantly different from 0 in

Table 1 Influence of day length and sex on frequencies (per cent) of dark, intermediate and pale larvae in Araschnia levana, and brown (dark) and green (pale) pupae in Inachis io

\begin{tabular}{|c|c|c|c|c|c|c|c|}
\hline & \multicolumn{4}{|c|}{ A. levana larvae } & \multicolumn{3}{|c|}{ I. io pupae } \\
\hline & Dark & Intermediate & Pale & $N$ & Dark & Pale & $N$ \\
\hline Overall & 38.5 & 16.8 & 44.6 & 742 & 31.5 & 68.5 & 995 \\
\hline $\begin{array}{l}\text { Long day } \\
\text { Short day }\end{array}$ & $\begin{array}{l}36.1 \\
41.3\end{array}$ & $\begin{array}{l}15.9 \\
17.9\end{array}$ & $\begin{array}{l}48.0 \\
40.8\end{array}$ & $\begin{array}{l}396 \\
346\end{array}$ & $\begin{array}{l}26.4 \\
37.4\end{array}$ & $\begin{array}{l}73.6 \\
62.6\end{array}$ & $\begin{array}{l}538 \\
457\end{array}$ \\
\hline $\begin{array}{l}\text { Males } \\
\text { Females }\end{array}$ & $\begin{array}{l}41.2 \\
39.8\end{array}$ & $\begin{array}{l}17.4 \\
12.9\end{array}$ & $\begin{array}{l}41.5 \\
47.3\end{array}$ & $\begin{array}{l}311 \\
279\end{array}$ & $\begin{array}{l}32.7 \\
30.5\end{array}$ & $\begin{array}{l}67.3 \\
69.5\end{array}$ & $\begin{array}{l}502 \\
493\end{array}$ \\
\hline
\end{tabular}

(C) The Genetical Society of Great Britain, Heredity, 82, 57-68. 
all instars with the exception of LD females (Table 3). Genetic correlations $\left(r_{\mathrm{G}} \mathrm{s}\right)$ within traits between SD and LD are also high and significantly different from 0 in all instars. Genetic correlation between development time in the 5th and preceding instars is, however, weak and not significantly different from 0 (Table 3 ).

Pupal periods of summer forms are shorter for males than for females with significant $h^{2}$ s for males $(0.488, P<0.01)$, but not for females $(0.161$, NS). The pupal stage for spring pupae consisted of three periods: a fixed period of 4 weeks after pupation, a period in the cold room until 1 February, and the period between overwintering and adult eclosion. The last period was shorter for males than for females, did not differ between SD and LD pupae, and was not related to the length of the period in the cold room. Heritabilities for the pupal period after overwintering were low $(<0.18)$ and not significantly different from 0 .

Adult size is larger in females and summer forms (Fig. 3). Heritabilities for adult size are low for LD spring forms (males 0.199; females 0.248; both NS), but larger and significantly different from 0 for summer and SD spring forms (Table 3). Genetic correlations for size across environments are moderate and significant only for females (Table 3 ).

\section{Influence of juvenile melanization on life history in}

\section{A. levana}

Melanization influences larval development time and adult size (Table 2). Dark larvae have short 5th instar periods but instars 1-4 take longer relative to pale larvae; the difference is especially large in LD (Fig. 3). The length of the pupal stage is not different between pale and dark larvae. Adult wing size from dark larvae is larger (Fig. 3), especially in $\mathrm{SD}$, resulting in a significant daylength by colour interaction (Table 2).

Influence of pupal colour on development time and adult size is low at the phenotypic level and mostly not significant $(r=-0.203$ to +0.198$)$. Only SD males with paler pupae have longer 5 th instars $(r=0.300, P=0.008)$. Genetic correlations between pupal colour and development time are stronger

Table $2 F$-values for multifactor ANOvas for adult and life history traits in relation to sex, daylength/form and juvenile coloration in Araschnia levana and Inachis io. Levels for the daylength/form factor are long day/summer form, long day/spring form, short day/spring form for $A$. levana, except for extent of black spot which was only measured on spring forms, and long day and short day for I. io. Juvenile colour refers to larvae for A. levana, to pupae for Inachis io

\begin{tabular}{|c|c|c|c|c|}
\hline & $\begin{array}{l}\text { Daylength } \\
\text { /form }\end{array}$ & Sex & $\begin{array}{l}\text { Juvenile } \\
\text { colour }\end{array}$ & $\begin{array}{l}\text { Significant } \\
\text { interactions }\end{array}$ \\
\hline \multicolumn{5}{|c|}{ Larval development time } \\
\hline A. levana, I-IV & $131.59^{* * * *}$ & $3.186 \dagger$ & $5.493^{* *}$ & None \\
\hline A. levana, $\mathrm{V}$ & $3641.06^{* * * *}$ & $28.02 * * * *$ & $38.03^{* * * *}$ & $\mathrm{D} \times \mathrm{S}, 3.59^{*}$ \\
\hline I. io, $\mathrm{I}-\mathrm{V}$ & $7.678^{* *}$ & $23.15^{* * * *}$ & $16.14 * * *$ & $\mathrm{D} \times \mathrm{J}, 20.98^{* * * *}$ \\
\hline \multicolumn{5}{|c|}{ Pupal development time } \\
\hline A. levana & $776.96^{* * * *}$ & $1.39 \mathrm{NS}$ & $0.14 \mathrm{NS}$ & $\mathrm{D} \times \mathrm{S}, 5.59^{*}$ \\
\hline I. io & $15.90^{* * *}$ & $6.79^{* *}$ & $1.59 \mathrm{NS}$ & None \\
\hline \multicolumn{5}{|l|}{ Adult wing size } \\
\hline A. levana & $416.73^{* * * *}$ & $503.96^{* * * *}$ & $9.741^{* * *}$ & $\mathrm{D} \times \mathrm{J}, 2.94 *$ \\
\hline I. io & $79.48^{* * * *}$ & $708.70^{* * * *}$ & $15.73^{* * * *}$ & None \\
\hline \multicolumn{5}{|l|}{ Pupal melanization } \\
\hline A. levana & $48.57 * * * *$ & $9.25^{* *}$ & $3.44^{*}$ & None \\
\hline \multicolumn{5}{|c|}{ Adult melanization: intensity } \\
\hline A. levana, band & $4777.21 * * * *$ & $26.04 * * * *$ & $5.48^{* *}$ & $\mathrm{D} \times \mathrm{S}, 21.03^{* * *}$ \\
\hline I. io, wing & $0.358 \mathrm{NS}$ & $174.57 * * * *$ & $6.452^{*}$ & $\mathrm{D} \times \mathrm{J}, 4.73^{*}$ \\
\hline \multicolumn{5}{|c|}{ Adult melanization: extent } \\
\hline A. levana, wing & $33.30^{* * * *}$ & $184.43^{* * * *}$ & $2.12 \mathrm{NS}$ & $\mathrm{D} \times \mathrm{S}, 9.54^{* * *}$ \\
\hline A. levana, spot & $3.445 \dagger$ & $72.41 * * * *$ & $0.83 \mathrm{NS}$ & None \\
\hline I. io, spot & $2.218 \mathrm{NS}$ & $24.82 * * * *$ & $7.54 * * *$ & $\mathrm{D} \times \mathrm{J}, 4.53^{*}$ \\
\hline
\end{tabular}

$\dagger P<0.1,{ }^{*} P<0.05,{ }^{* *} P<0.01,{ }^{* * *} P<0.001,{ }^{* * * *} P<0.0001$; NS, not significant. 
than phenotypic correlations and mostly significant (Table 4). Dark pupae are genetically associated with longer development times in the first four instars, but shorter development times in the 5th larval stage. Genetic correlations of pupal coloration with pupal development time and wing size are not significant.

Heritabilities change little when the effect of larval coloration is removed and remain about the same in dark larvae as in the complete data set. Unfortunately, insufficient pale larvae in different families were available for reliable estimates. Removal of the influence of larval colour has the effect that genetic correlations between LD and SD development times decrease to weak, nonsignificant values for the 5 th instar (Table 3), but has no effect for instars 1-4. The genetic correlation between SD and LD for adult size increased to strong significant correlations when the influence of larval colour was removed.

\section{Pupal melanization in I. io}

About two-thirds of I. io pupae are pale (Table 1). Frequencies are similar in males and females $\left(\chi_{1}^{2}=0.58, \mathrm{NS}\right)$, but SD produces significantly more dark pupae $\left(\chi_{1}^{2}=13.9, P=0.0002\right)$. Comparing the coloration within dark and pale categories I found no significant difference between the sexes, but SD pupae were somewhat darker than LD ones. The percentage of dark pupae within families of $I$. io ranges from 17.2 to 54.4. The correlation between short and long days of the percentage of dark pupae in the different families is not significant $(r=0.401$,

\section{Araschnia levana}
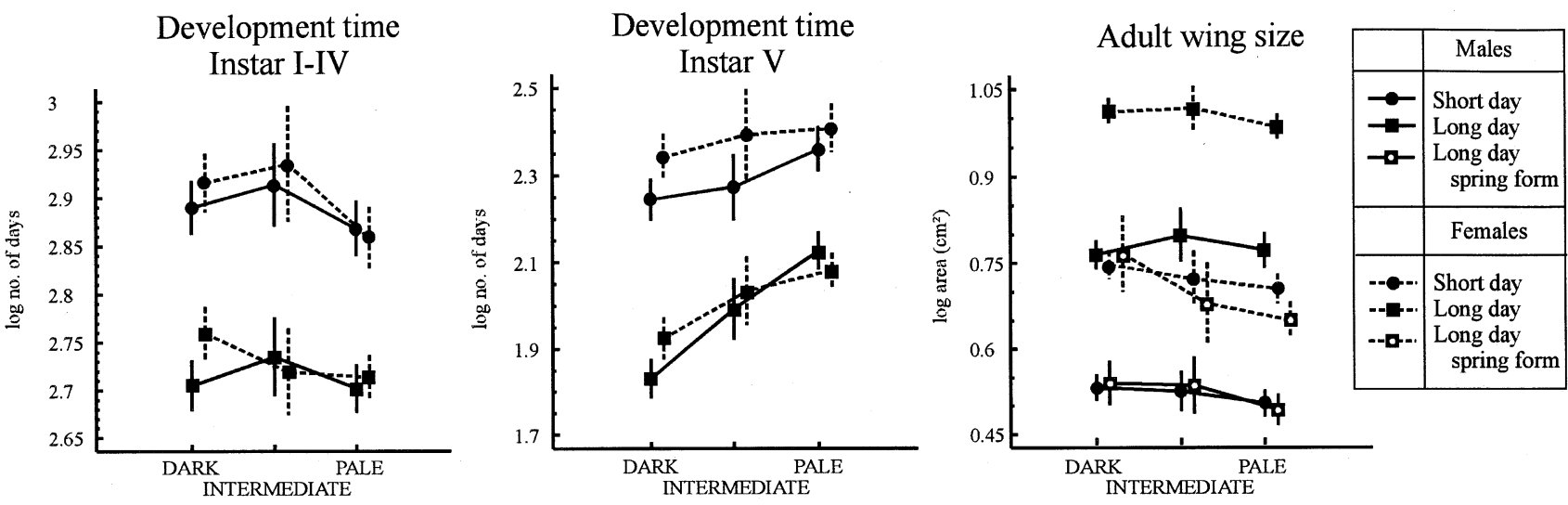

\section{Inachis io}
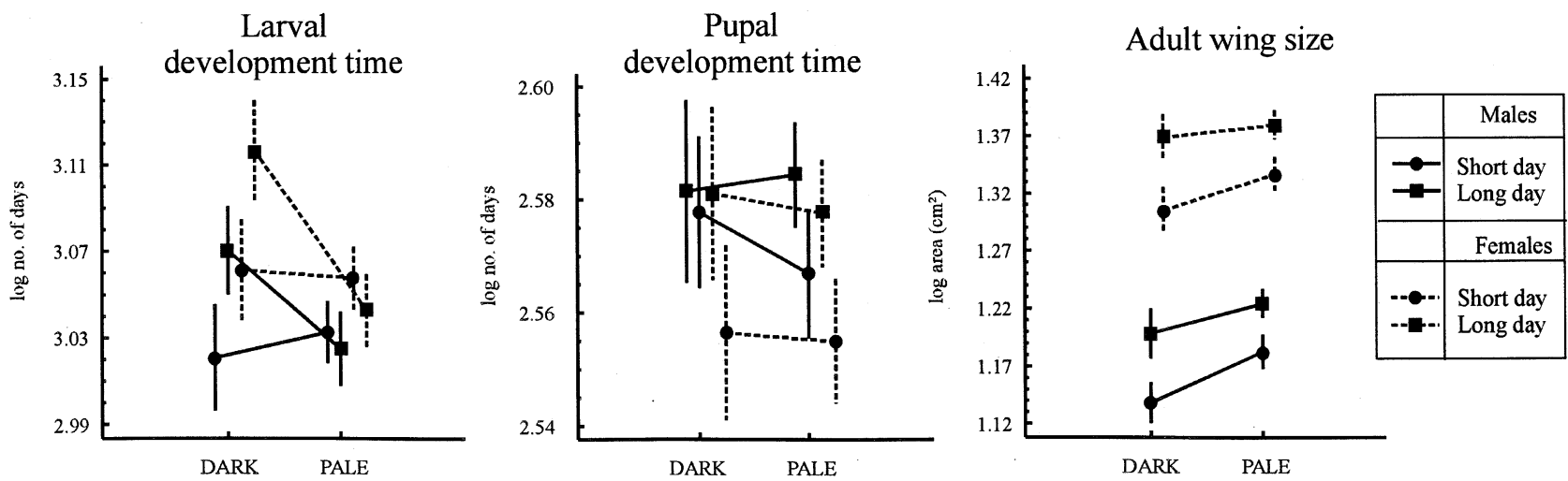

Fig. 3 Life history traits and juvenile coloration. Juvenile coloration on the $x$-axes represents larval colour categories for Araschnia levana and pupal colour categories for Inachis io. Solid lines represent males, dashed lines females. Average indicated by circles is for short days, by squares for long days. Adult wing size in $A$. levana is given separately for summer forms (solid squares) and spring forms (squares with a white dot). Vertical lines represent $95 \%$ confidence intervals. 
Table 3 Genetics of larval development time in Araschnia levana. All estimates are calculated with Restricted Error Maximum Likelihood Analysis. Genetic correlations in bold on diagonals are within traits across daylengths; other $r_{\mathrm{G}} \mathrm{s}$ are between traits within daylengths. Estimates are given for the whole data set, and for a reduced data set with only the dark larvae included. The reduced data set with only pale larvae did not converge. Long day size only spring forms analysed

\begin{tabular}{|c|c|c|c|c|c|c|c|c|c|}
\hline & & \multicolumn{4}{|c|}{ Males } & \multicolumn{4}{|c|}{ Females } \\
\hline & & $h^{2}$ & I-IV & V & Size & $h^{2}$ & I-IV & V & Size \\
\hline \multicolumn{10}{|c|}{ All larvae } \\
\hline \multirow[t]{2}{*}{ I-IV } & Short Day & $0.877 * * * *$ & $0.791 * * * * *$ & & & $0.864 * * * *$ & $0.774 * * * * *$ & & \\
\hline & Long Day & $0.902 * * * *$ & & & & $0.997 * * * *$ & & & \\
\hline \multirow[t]{2}{*}{ V } & Short Day & $0.364^{* * *}$ & 0.241 & $0.725 * * * *$ & & $0.771 * * * *$ & -0.181 & $0.416^{* *}$ & \\
\hline & Long Day & $0.941 * * * *$ & 0.074 & & & 0.179 & 0.094 & & \\
\hline \multirow[t]{2}{*}{ Size } & Short Day & 0.496 **** & $0.448^{*}$ & 0.002 & 0.280 & $0.591 * * * *$ & 0.377 & -0.388 & $0.459 *$ \\
\hline & Long Day & $0.694 * * * *$ & 0.240 & -0.017 & & $0.307 * * *$ & 0.259 & $-0.601^{*}$ & \\
\hline \multicolumn{10}{|c|}{ Dark larvae } \\
\hline \multirow[t]{2}{*}{ I-IV } & Short Day & $1.105^{* * * *}$ & $0.740^{* *}$ & & & $0.974 * * * *$ & $0.776^{* * *}$ & & \\
\hline & Long Day & $0.875^{* * *}$ & & & & $1.110^{* * * *}$ & & & \\
\hline \multirow[t]{2}{*}{ V } & Short Day & $0.675^{* *}$ & $0.563^{*}$ & 0.147 & & 0.208 & n.c. & 0.176 & \\
\hline & Long Day & $0.694 * * * *$ & 0.278 & & & 0.247 & 0.511 & & \\
\hline \multirow[t]{2}{*}{ Size } & Short Day & $0.523^{*}$ & 0.184 & 0.114 & $0.864 * * *$ & $0.527 * * *$ & 0.191 & -0.274 & $0.793 * *$ \\
\hline & Long Day & $0.891^{* * *}$ & $0.740^{*}$ & 0.256 & & $0.817^{* * *}$ & 0.373 & $-0.715^{*}$ & \\
\hline
\end{tabular}

I-IV, development time of instars 1-4; V, development time of 5th instar.

${ }^{*} P<0.05,{ }^{* *} P<0.01,{ }^{* * *} P<0.001,{ }^{* * * *} P<0.0001 ;$ n.c., not converged.

Table 4 Genetic correlations between pupal coloration, adult wing pattern and life history traits. Full-sib estimates from Restricted Error Maximum Likelihood analysis

\begin{tabular}{|c|c|c|c|c|c|c|c|}
\hline & & \multicolumn{3}{|c|}{ Araschnia levana } & \multicolumn{3}{|c|}{ Inachis io } \\
\hline & & \multicolumn{2}{|c|}{ Spring form } & \multirow{2}{*}{$\begin{array}{c}\text { Summer form } \\
\text { Long day }\end{array}$} & & \multirow[b]{2}{*}{ Short day } & \multirow[b]{2}{*}{ Long das } \\
\hline & & Short day & Long day & & & & \\
\hline \multicolumn{8}{|c|}{ Development time } \\
\hline \multirow[t]{2}{*}{ Larval I-IV } & Male & $-0.729 *$ & & \multirow{2}{*}{$\begin{array}{l}-0.546 \dagger \\
-0.612^{*}\end{array}$} & Larval & -0.159 & -0.266 \\
\hline & Female & -0.192 & & & & $-0.957^{*}$ & 0.202 \\
\hline \multirow[t]{2}{*}{ Larval V } & Male & 0.194 & & $0.663^{*}$ & & & \\
\hline & Female & $0.865 \dagger$ & & $0.649^{*}$ & & & \\
\hline \multirow{2}{*}{ Pupal } & Male & 0.455 & 0.339 & -0.530 & Pupal & -0.004 & 0.192 \\
\hline & Female & -0.475 & $-1.344^{*}$ & -0.511 & & 0.020 & -0.003 \\
\hline \multicolumn{8}{|l|}{ Adult size } \\
\hline \multirow[t]{2}{*}{ Wing area } & Male & -0.704 & -0.824 & 0.127 & Wing area & 0.153 & 0.485 \\
\hline & Female & -0.153 & n.c. & -0.261 & & $0.716 \dagger$ & 0.542 \\
\hline \multicolumn{8}{|c|}{ Adult melanization, intensity } \\
\hline \multirow[t]{2}{*}{ Band } & Male & 0.192 & 0.114 & 0.267 & Wing & 0.530 & 0.200 \\
\hline & Female & -0.175 & 0.430 & 0.083 & & 0.311 & 0.213 \\
\hline \multicolumn{8}{|c|}{ Adult melanization, extent } \\
\hline \multirow[t]{2}{*}{ Spot } & Male & 0.229 & -0.596 & & Spot & -0.722 & $-0.837^{*}$ \\
\hline & Female & -1.115 & -0.360 & & & -0.367 & -0.824 \\
\hline \multirow{2}{*}{ Wing } & Male & 0.374 & -0.109 & 0.230 & & & \\
\hline & Female & -0.266 & n.c. & 0.231 & & & \\
\hline
\end{tabular}

$\dagger P<0.1,{ }^{*} P<0.05$; n.c., not converged. 
$n=11, P=0.20)$. Heritability of pupal coloration as a threshold trait is rather low (LD 0.057; SD 0.270) and only significant for SD.

\section{Life history traits in I. io}

Females had longer larval development times than males, but shorter pupal periods (Fig. 3). Larvae took longer but pupae took less time to develop in SD than in LD. Heritabilities for larval development time are rather high (males: LD 0.506, SD 0.583; females: LD 0.434, SD 0.522; all $P<0.0001$ ) and for pupal development time are moderate in LD (males 0.251 ; females 0.366 ; both $P<0.0001$ ), but low in SD (males 0.007, NS; females 0.143, $P<0.05$ ). Adult females are larger, as are LD adults (Fig. 3). Heritabilities for adult wing size are around $30 \%$ (males: LD 0.336, SD 0.250; females: LD 0.316, SD 0.320; all $P<0.0001)$.

\section{Pupal melanization and life history traits in I. io}

Larval development time was longer for dark than for pale $I$. io pupae, especially in $\mathrm{LD}$. There was no difference in pupal development time between pale and dark pupae (Fig. 3, Table 2). Dark I. io pupae produce smaller adults in both LD and SD. Variation in pupal coloration within dark and pale categories did not correlate significantly with larval or pupal development time. In SD larger male adults eclosed from paler pupae within both pale and dark pupal classes. At the genetic level the correlation between pupal colour and larval development time is significantly different from 0 for SD females, but the other correlations between pupal coloration and life history variables are not significant (Table 4). Heritabilities and genetic correlations remain similar when analysed separately for dark and pale pupae.

\section{Melanization across life stages}

Summer forms of $A$. levana have relatively larger black areas than spring forms, but there is no difference between spring forms from LD and SD. Heritability for adult melanization is high (details in Windig \& Lammar, 1998). The extent of black in the adult stage is similar for pale and dark larval categories (Table 2). Both spring and summer forms have darker bands in pale larval categories. Darker $A$. levana larvae produce darker pupae. No significant genetic correlations are found between pupal coloration and wing pattern (Table 4). Faster growing 5th instars of $A$. levana in LD more often produce summer forms (Windig \& Lammar, 1998). Consequently dark larvae produce more summer forms $(78.9 \%)$ than intermediate larvae $(62.7 \%)$ and pale larvae $(56.0 \%)$ and the difference is significant $\left(\chi_{2}^{2}=16.77, P=0.0002\right)$.

In $I$. io there is no difference in adult melanization between SD and LD. Females have smaller black spots and black coloration is less intense. Both the size of black spots and the intensity of black coloration have high $h^{2} \mathrm{~s}(0.702-1.069)$. Dark I. io pupae produce adults with significantly larger black spots. The difference between dark and pale pupae is especially large under SD resulting in a significant day length by juvenile colour interaction (Table 2). Dark pupae also produce adults with paler wings especially under LD. Genetic correlations between pupal colour and adult melanization are in the same direction as phenotypic effects (Table 4), but only one is significant (between pupal coloration and spot size in LD males).

\section{Discussion}

There is considerable variation in juvenile melanization, and correlations with adult wing pattern and life history traits are often substantial. In general, most traits have high $h^{2}$ s and some genetic correlations are similar or stronger than the phenotypic correlations. Consequently selection which favours darker or paler pupae or larvae may also influence adult wing pattern and life history traits or vice versa. It has been shown that melanization may have important consequences for the survival and fitness of individuals in all stages. From the experiments described here it is clear that for a full understanding of all the ecological and evolutionary implications the different life stages should not be regarded in isolation.

\section{Genetic aspects}

The percentages of pale and dark A. levana larvae do not agree with a simple one-locus diallelic system. However, if intermediates may at times belong either to dark or pale categories the hypothesis remains open. The range of frequencies of black individuals within families $(0-100 \%)$, their consistency across environments and their influence on genetic correlations all suggest, however, that pupal colour is largely if not completely genetically determined. Crossing experiments are needed for a better understanding.

Plasticity is involved in larval coloration in Mamestra brassicae (Goulson, 1994) and Aglais 
urticae (I. Convie, Louvain-la-Neuve, pers. comm.) where larvae develop a paler coloration under higher temperature. The presence of broods with only dark or pale larvae in both spring and summer (pers. obs.) suggests, however, that plasticity is less important, or even absent in A. levana. Variation in larval density correlates in some species with variation in melanization (e.g. Hojdat, 1970), but was held constant across families in this experiment. Moreover, if $A$. levana is mass-reared the frequency of black individuals is unaffected (pers. obs.).

Larval melanization in A. levana influences plasticity of development time in the 5th instar and adult size. Dark genotypes have shorter development times than pale genotypes both in SD and LD, and the increase in size from SD to LD is larger in pale than in dark genotypes (Fig. 3). This is reflected in the genetic correlations between SD and LD: high for duration of the 5th instar, low for adult size. When only dark individuals are analysed these correlations change to low and high, respectively (Table 3). What kinds of genes influence genetic variation in plasticity is a much debated question in evolutionary biology (Via et al., 1995; Pigliucci, 1996). This debate suffers from a lack of information on the actual genes influencing plasticity (Windig et al., in press). High genetic correlations across environments indicate genes with similar effects across environments and consequently low genetic variation for plasticity. Thus genetic variation in plasticity is low for the duration of the 5th instar and high for adult size, mainly because of genetic variation in melanization. This makes larval melanization in $A$. levana a rare example of a gene influencing genetic variation in plasticity.

Plasticity is known to be an important element in the determination of the pupal colour in $I$. io (Brecher, 1923; Starnecker, 1996). In general, dark pupae are formed against dark backgrounds and vice versa. In the experiments described here more dark pupae are formed under SD. Pupae of Polygonia c-aureum raised under SD are also darker (Hiroyoshi, 1992).

\section{Melanin and life history traits are not independent}

Some of the results suggest a trade-off between melanin production and life history traits: individuals with dark juvenile stages had slow development in earlier instars in both species and became small adults for I. io. However, dark A. levana larvae result in large adults in SD and slow larval growth of dark pupae in $I$. io cannot result from a trade-off with production of melanin or its precursors. Deter- mination of pupal colour by pupation site colour in I. io does not occur until the pre-pupal stage (Starnecker, 1996). Regardless of its larval development time a dark pupa can always be formed. Goulson (1994) states that small size of melanized larvae may be a general phenomenon, but he did not find differences in development time or adult weight.

There are two possible explanations, other than trade-offs, for slow growing larvae producing dark pupae in $I$. io. They may develop a different sensitivity from fast growing larvae for background colour or they may search for dark pupation sites such as under their food (a leaf) in this experiment, or, in the field away from their host plant. In Ephestia kuhniella adult moths of a melanized strain are more active relative to a pale strain; this is possibly caused by the presence of dopamine, a precursor of melanin, but also a neurotransmitter (M. Verhoog, Leiden, pers. comm.).

Faster growth rate of black 5th instars, relative to pale larvae, in A. levana is probably the consequence of their coloration. It is well known that black insects heat up fast and have high growth rates under relatively cool conditions (Dennis, 1993), like the ones $\left(20^{\circ} \mathrm{C}\right)$ that were used here. At high temperatures they may risk overheating. We need to know the effect on larval development time of coloration over a range of temperatures. Absence of a phenotypic relationship between melanization in the pupal stage and life history traits can be explained by the low level of variation in melanization in pupae.

Both species probably benefit from faster growth rates under some circumstances, because this may allow a small percentage of them to have an extra generation, as occurs for both species in the field in Belgium. Selection in the field may favour dark $A$. levana larvae with a fast growth rate in spring, and pale larvae in summer. Dark larvae risk overheating in summer. Furthermore, towards the end of summer dark larvae may be maladaptive as they produce more nondiapausing summer forms than pale larvae. Alternating selection regimes may thus explain how genetic variation for larval coloration is maintained. Thermoregulation in I. io larvae differs from A. levana as the former is a basker. The risk of overheating in summer can be overcome by reducing basking time (Porter, 1982); hence there is no advantage for pale larvae at that time of the year.

\section{Melanin across life stages is not independent}

Melanization is not independent between life stages. For intensity of melanization a negative relationship 
between juveniles and adults exists, for extent a positive one. Interestingly, at the physiological level the same class of hormones that is known to be involved in the production of pupal colour, neuropeptides (Starnecker, 1996), is thought to be involved in the intensity of coloration in adult wing patterns, whereas another class of hormones, ecdysones, is thought to be involved in the size of pattern elements (Koch, 1992).

\section{Acknow ledgements}

I am grateful to the research group on ecology and evolution of the RUCA, especially Jan Scheirs and Luc de Bruyn for providing space in their climate chambers. Pascal Lammar raised many map butterflies and both he and David Curry helped at peak emergence time of peacocks in summer. Thanks also to Sören Nylin, Christer Wicklund and anonymous reviewers for comments on an earlier version of this paper. The study was supported by a grant from the EEC Human Capital and Mobility programme (contract no. ERBCHBICT941145).

\section{References}

BLOIS, M. s. 1978. The melanins: their synthesis and structure. In: Smith, K. C. (ed.) Photochemical and Photobiological Reviews, vol. 3, pp. 115-134. Plenum Press, New York.

BRAKEFIELD, P. M. AND VAN NOORDWIJK, A. J. 1985. The genetics of spot pattern characters in the meadow brown butterfly Maniola jurtina (Lepidoptera: Satyrinae). Heredity, 54, 275-584.

BReCHER, L. 1923. Die Puppenfärbungen der Vanessiden (Vanessa Io, V. urticae). Arch. mikroskop. Anat. Entwicklungsmechanik, 102, 517-548.

DE JONG, P. W., GUSSEKLOO, S. AND BRAKEFIELD, P. M. 1996. Differences in thermal balance, body temperature and activity between non-melanic and melanic two-spot ladybird beetles (Adalia bipunctata) under controlled conditions. J. Exp. Biol., 199, 2655-2666.

DENNIS, R. L. H. 1993. Butterflies and Climate Change. Manchester University Press, Manchester.

FIELDS, P. G. AND McNEIL, J. N. 1988. The importance of seasonal variation in hair coloration for thermoregulation of Ctenucha virginica larvae (Lepidoptera: Arctiidae). Phys. Ent., 13, 165-175.

GOULSON, D. 1994. Determination of larval melanization in the moth, Mamestra brassicae, and the role of melanin in thermoregulation. Heredity, 73, 471-479.

GRANT, B. S., OWEN, D. F. AND ClARKE, C. A. 1996. Parallel rise and fall of melanic peppered moths in America and Britain. J. Hered., 87, 351-357.

HAZEL, W. N. AND WEST, D. A. 1996. Pupation site prefer- ence and environmentally cued pupal colour dimorphism in the swallowtail butterfly Papilio polyxenes Fabr. (Lepidoptera: Papilionidae). Biol. J. Linn. Soc., 57, 81-87.

HIROYOSHI, s. 1992. Effects of photoperiod and temperature on several pupal characters associated with imaginal polyphenism in Polygonia c-aureum. Appl. Ent. Zool., 27, 155-159.

HOJDAT, s. H. 1970. Effects of crowding on colour, size and larval activity of Spodoptera littoralis (Lepidoptera: Noctuidae). Entomologia exp. appl., 13, 97-106.

HOLLOWAY, G. J., BRAKEFIELD, P. M., DE JONG, P. W., OTTENHEIM, M. M., DE VOS, H., KESBEKE, F. ET AL. 1995. A quantitative genetic analysis of an aposematic colour pattern and its ecological implications. Phil. Trans. R. Soc. B, 348, 373-379.

Kettlewell, B. 1973. The Evolution of Melanism. Clarendon Press, Oxford.

KINGSOLVER, J. G. 1995. Viability selection on polyphenic traits: wing melanin pattern in Western White Butterflies. Evolution, 49, 932-941.

KINGSOlver, J. G. AND WIERnASz, D. C. 1991. Development, function, and the quantitative genetics of wing melanin pattern in Pieris butterflies. Evolution, 45, 1480-1492.

косн, Р. в. 1992. Seasonal polyphenism in butterflies: a hormonally controlled phenomenon of pattern formation. Zool. Jb. (Physiol.), 96, 227-240.

MAES, D. AND VAN DIJCK, H. 1996. A documented red list of the butterflies of Flanders (in Dutch with an English summary). Med. Ins. Natuurbehoud, 1, 1-154.

MAJERUS, M. E. N. 1998. Melanism: Evolution in Action. Oxford University Press, Oxford.

MOUSSEAU, T. AND ROFF, D. A. 1987. Natural selection and the heritability of fitness components. Heredity, 59, 181-197.

NYLIN, S. AND GOTTHARD, K. 1998. Plasticity in life-history traits. Ann. Rev. Ent., 43, 63-83.

PIGLIUCCI, M. 1996. Modelling phenotypic plasticity. 2. Do genetic correlations matter? Heredity, 77, 453-460.

PORTER, K. 1982. Basking behaviour in larvae of the butterfly Euphydryas aurinia. Oikos, 38, 308-312.

PULlin, A. s. 1986. Influence of the foodplant Urtica dioica on larval development, feeding efficiency and voltinism of a specialist insect Inachis io. Hol. Ecol., 9, 72-78.

ROFF, D. A. 1997. Evolutionary Quantitative Genetics. Chapman and Hall, New York.

SHAW, R. G., PLATENKAMP, G. A. J., SHAW, F. H. AND PODOLSKY, R. H. 1995. Quantitative genetics of response to competitors in Nemophila menziesii: a field experiment. Genetics, 139, 397-406.

Smith, D. A. S., Shoesmith, E. A. AND Smith, A. G. 1988. Pupal polymorphism in the butterfly Danaus chrysippus (L.): environmental, seasonal and genetic influences. Biol. J. Linn. Soc., 33, 17-50.

STARNECKER, G. 1996. Color preference for pupation sites of the butterfly larvae of Inachis io and the significance 
of the pupal melanization reducing factor. Naturwissenschaften, 83, 474-476.

STEARns, s. C. 1983. The Evolution of Life Histories. Oxford University Press, Oxford.

VAN DYCK, H., MATTHYSEN, E. AND DHONDT, A. A. 1997.

The effect of wing colour on male behavioural strategies in the speckled wood butterfly. Anim. Behav., 53, 39-51.

VIA, S., GOMULKIEWICZ, R., DE JONG, G., SCHEINER, S. M., SCHLICHTING, C. D. AND VAN TIENDEREN, P. H. 1995. Adaptive phenotypic plasticity: consensus and controversy. Trends Ecol. Evol., 10, 212-217.

WATt, w. B. 1968. Adaptive significance of pigment polymorphism in Colias butterflies I. Variation in melanin pigment in relation to thermoregulation. Evolution, 22, 437-458.

WIKLund, C. 1975. Pupal color polymorphism in Papilio machaon and the survival in the field of cryptic vs. non-cryptic pupae. Trans. R. Soc. Ent. Lond., 127, $73-84$.

WINDIG, J. J. 1991. Quantification of Lepidoptera wing patterns using an image analyser. J. Res. Lepid., 30, 82-94.

WINDIG, J. J. 1994a. Genetic correlations and reaction norms in wing pattern of the tropical butterfly Bicyclus anynana. Heredity, 73, 459-470.

WINDIG, J. J. 1994b. Reaction norms and the genetic basis of phenotypic plasticity in the wing pattern of the butterfly Bicyclus anynana. J. Evol. Biol., 7, 665-695.

WINDIG, J. J. AND LAMMAR, P. 1999. Evolutionary genetics of seasonal polyphenism in the map butterfly Araschnia levana (Nymphalidae; Lepidoptera). Evol. Ecol. Res., in press.

WINDIG, J. J., BRAKEFIELD, P. M., REITSMA, N. AND WILSON, J. G. M. 1994. Seasonal polyphenism in the wild: survey of wing pattern in five species of Bicyclus butterflies in Malawi. Ecol. Entomol., 19, 285-298.

WINDIG, J. J., DE KOVEL, C. G. M. AND DE JONG, G. 1999. Genetics and mechanics of plasticity. In: DeWitt, T. J. and Scheiner, S. M. (eds) Phenotypic Plasticity. Functional and Conceptual Approaches. Chapman and Hall, New York. 